\title{
The complexity of using resting myocardial perfusion to assess myocardial viability and predict functional recovery
}

\author{
Jennifer K. Lang, MD, and John M. Canty Jr., $M D^{a, b, c}$ \\ a Division of Cardiovascular Medicine and the Clinical and Translational Research Center, \\ Department of Medicine, University at Buffalo, Buffalo \\ b The Veterans Affairs Western New York Health Care System, Buffalo \\ c Clinical and Translational Research Center, University at Buffalo, Buffalo, NY
}

Received Apr 22, 2019; accepted Apr 23, 2019

doi: $10.1007 / \mathrm{s} 12350-019-01742-8$

\section{See related article, pp. 263-273}

The management of patients with coronary artery disease and left ventricular dysfunction has historically focused on identifying patients having viable dysfunctional myocardium with a high likelihood of at least partially reversible left ventricular dyssynergy. Observations in the early years of coronary bypass surgery identified the fact that some areas of contractile dysfunction that were originally thought to be irreversibly injured scar demonstrated functional improvement after revascularization. It was later demonstrated that these areas had reduced Thallium uptake at rest which was felt to reflect chronically reduced resting flow rather than myocardial fibrosis. These observations led to the concept of hibernating myocardium. The need to identify viable dysfunctional myocardium was largely driven by the fact that many of these patients were limited by symptoms of heart failure rather than angina and, because of severely reduced ejection fractions, were considered at high risk for undergoing coronary artery bypass surgery. The preoperative demonstration of viability vs nonviable scar when resting flow was reduced was reassuring to the cardiac surgeon in that surgical revascularization was likely to improve myocardial

Reprint requests: John M. Canty, Jr., MD, Clinical and Translational Research Center, University at Buffalo, Suite 7030, 875 Ellicott Street, Buffalo, NY 14203; canty@buffalo.edu

J Nucl Cardiol 2021;28:274-7.

$1071-3581 / \$ 34.00$

Copyright (C) 2019 This is a U.S. government work and its text is not subject to copyright protection in the United States; however, its text may be subject to foreign copyright protection. function and reduce the likelihood of postoperative pump dysfunction immediately following cardiopulmonary bypass.

Over the years, many complimentary imaging approaches have been developed to distinguish viable dysfunctional myocardium from scar and predict functional recovery after revascularization. ${ }^{1}$ Initial approaches evaluated resting perfusion by employing planar and then SPECT nuclear imaging with myocyte cellular integrity demonstrated by the delayed uptake of Thallium-201 $\left({ }^{201} \mathrm{Tl}\right)$ at rest or with ${ }^{201} \mathrm{Tl}$ stress/reinjection protocols. These were followed by PET approaches evaluating the metabolic activity of myocytes vs scar with the uptake of ${ }^{18} \mathrm{~F}$-2-deoxyglucose (FDG) under a variety of insulin and glucose loading protocols. The PET approaches also overcame attenuation artifacts that confound resting SPECT imaging. A PET mismatch with reduced flow and relatively preserved FDG uptake has been established as the most sensitive approach to identify viability. Alternative imaging approaches have evaluated regional contractile reserve following short-term inotropic stimulation with dobutamine which, when present, is also predictive of functional recovery. Finally, direct assessment of myocardial infarction became possible using MRI imaging of late $\mathrm{Gd}$ uptake. In contrast to previous techniques, cardiac MRI can directly quantify the volume as well as the transmural extent of infarction which has also been demonstrated to be a strong predictor of functional recovery. ${ }^{2}$

Regardless of the imaging approach used, all are associated with false positive and false negative prediction of functional recovery in individual patients. ${ }^{1}$ This to a large extent reflects heterogeneity in the pathological substrate causing contractile dysfunction. Some of the underlying causes of viable dysfunctional 
myocardium can be distinguished based on their effect on resting flow. For example, many patients exhibit contractile dysfunction with normal resting perfusion that can arise from acute ischemia as well as chronic repetitive ischemia or "chronic stunning". 1,3 It can also arise in the absence of ischemia from ventricular remodeling. While myocardium is always considered viable when resting perfusion is normal, it does not always predict functional recovery. Likewise, even when segmental coronary disease is absent and subendocardial scar is excluded by late contrast enhanced gadolinium magnetic resonance imaging (Gd-MRI), a significant minority of patients have dysfunctional myocardium that does not improve after revascularization. Some of this reflects irreversible myocyte loss and molecular remodeling that does not reverse after revascularization. In circumstances where resting regional flow is reduced, the situation becomes more complicated. Here, reductions in resting flow can reflect hibernating myocardium. On the other hand, a similar reduction in average transmural flow can also arise from an admixture of normal myocardium and subendocardial infarction. While some have challenged the concept of contractile dysfunction in association with reduced resting flow and the absence of infarction, preclinical studies from our laboratory as well as others demonstrate modest reductions in resting flow that are greatest in the subendocardium in the absence of infarction. ${ }^{4}$ Furthermore, studies quantifying perfusion using deconvolution of dynamic myocardial Gd-MRI uptake have demonstrated reductions in resting flow in the absence of late $\mathrm{Gd}$ uptake indicative of scar. $^{5}$ In subendocardial infarction, the degree of functional improvement is inversely related to the transmural extent of infarction with little recovery when this is greater than $50 \% .^{2}$ Unfortunately, even when infarction is absent in hibernating myocardium, there is myocyte loss and molecular remodeling that can explain incomplete functional recovery in the absence of infarction. ${ }^{6}$

Quantitative kinetic analysis of PET radiopharmaceuticals can assess perfusion in $\mathrm{ml} / \mathrm{min}$ per gram of tissue along with a variety of computational parameters. Quantitation of resting perfusion is particularly attractive since myocardial fibrotic tissue has an extremely low perfusion. ${ }^{1}$ While viability could be assessed without the need for additional advanced imaging with such an approach, prior results based upon quantifying resting flow have been variable with limited data available to establish the predictive ability of specific parameters in individual patients. ${ }^{7-13}$ In this issue of the Journal, Benz and colleagues determined whether quantitative PET parameters can differentiate viable dysfunctional myocardium from scar in patients with ischemic cardiomyopathy. ${ }^{14}$ Since ${ }^{13} \mathrm{NH} 3$ is actively metabolized by cells, modeling tracer kinetics beyond the initial uptake can characterize retention within viable cardiac myocytes. Along these lines, the rate of ${ }^{13} \mathrm{NH} 3$ washout (k2) has been suggested as a marker of tissue viability with high diagnostic accuracy. ${ }^{8}$ To test this, the authors conducted a single site retrospective cohort study looking at 180 patients with ischemic cardiomyopathy (average LVEF 33\%) who underwent combined ${ }^{13} \mathrm{NH} 3$ and ${ }^{18}$ FDG PET for clinical indications. Conventional criteria using insulin stimulated ${ }^{18} \mathrm{FDG}$ uptake and resting perfusion were used to identify segments as viable, hibernating, or scar. They applied a 17 -segment model (excluding segments with mixed patterns) and assessed the diagnostic accuracy of rest and stress myocardial blood flow, myocardial flow reserve, $\mathrm{k} 2$, and the volume of distribution. Out of all the kinetic parameters assessed, resting blood flow demonstrated the most significant difference between hibernating myocardium and scar $\left(0.68 \mathrm{~mL} \cdot \mathrm{min}^{-1} \cdot \mathrm{g}^{-1} \quad\right.$ vs $\left.0.80 \mathrm{~mL} \cdot \mathrm{min}^{-1} \cdot \mathrm{g}^{-1}, \quad p<0.001\right) \quad$ with an optimal threshold for viability of $0.66 \mathrm{~mL} \cdot \mathrm{min}^{-1} \cdot \mathrm{g}^{-1}$ and an AUC of 0.635 [0.599 to 0.671]. Unfortunately, the diagnostic accuracy of resting MBF to predict viability was only $57 \%$ [ $53 \%$ to $60 \%$ ] with a sensitivity of $77 \%$ and a specificity of $47 \%$. Importantly, the standard deviation of flow and other kinetic parameters derived from the ${ }^{13} \mathrm{NH}_{3}$ analysis was large. As a result, there was a large overlap among absolute measures of resting flow and other kinetic parameters between patients with viability vs. those with scar. While $82 \%$ of the patients had hibernating myocardium, this averaged only $4.4 \%$ of LV mass. Approximately 19\% (34 of 179 patients) had a clinically significant amount of hibernating myocardium (i.e., more than $10 \%$ of $\mathrm{LV}$ mass). While the authors recommend against assessing viability solely on the basis of quantitative ${ }^{13} \mathrm{NH}_{3}$ PET parameters, they raise the possibility that a flow less than $.45 \mathrm{~mL} \cdot \mathrm{min}^{-1} \cdot \mathrm{g}^{-1}$ could be used to identify patients without viability who do not require further viability testing. While others have previously advocated a similar concept, there may be important limitations in employing such an approach clinically.

The first issue relates to the inherent variability in quantitative resting flow in the absence of dysfunction. Average resting flow in normal subjects varies among isotopes and scanning protocols with a range of $\sim 0.6$ to $\sim 1.2 \mathrm{~mL} \cdot \mathrm{min}^{-1} \cdot \mathrm{g}^{-1}$ among studies. ${ }^{15}$ Moreover, the coefficient of variation (SD/Mean) among these studies varies widely ( $\pm 19 \%$ to $40 \%$ of the mean). Even using the lowest variation, the $95 \%$ confidence intervals for resting flow in a normal individual might vary from 0.36 to $1.44 \mathrm{~mL} \cdot \mathrm{min}^{-1} \cdot \mathrm{g}^{-1}$. Thus, even a significant number of normal subjects could fall below the proposed cut point of $0.45 \mathrm{~mL} \cdot \mathrm{min}^{-1} \cdot \mathrm{g}^{-1}$ proposed to identify 
irreversible injury. The second consideration relates to the presence of regional wall thinning in chronic coronary artery disease. Studies of hibernating myocardium using MRI before and after revascularization have demonstrated the presence of substantial regional wall thinning with variable amounts of infarction in a significant number of patients having reversible dysynergy. ${ }^{5,16}$ Interestingly, revascularization restores wall thickness in conjunction with improved contractile function which may reflect the myocyte proliferation reported after revascularization in preclinical studies. ${ }^{6}$ Due to partial volume effects with nuclear imaging, regional wall thinning in viable myocardium could magnify an apparent reduction in tracer activity below the proposed resting flow threshold. For example, if there was a $30 \%$ reduction in resting flow and a $30 \%$ reduction in end-diastolic wall thickness, the reduction in PET tracer uptake could approach $\sim 50 \%$ and resting flow could fall below the proposed cut point. Finally, there are sex differences in resting flow with generally higher quantitative values in women as compared to men which could importantly impact the precise threshold of flow used to identify viability. Thus, while we would agree with Benz and colleagues that the probability of significant viability decreases as absolute resting flow declines, defining a precise threshold may be impacted by several variables not taken into consideration in the present analysis.

A remaining question relates to the role of viability testing in contemporary management decisions. The present study identifies a relatively small amount of hibernating myocardium in even selected patients undergoing PET viability testing for the clinical suspicion of hibernating myocardium. Only one in five patients had more than $10 \%$ hibernating myocardium which some have suggested as the threshold for clinical benefit with revascularization. ${ }^{17}$ Nevertheless, even without demonstrating viability, the 10-year follow-up of the Surgical Treatment for Ischemic Heart Failure Extension Study (STICHES) demonstrated that patients with ischemic heart failure had a significant survival advantage with surgical revascularization. ${ }^{18}$ While viability testing was not required in this trial, the amount of viable myocardium was a determinate of prognosis yet did not differ among patients undergoing surgical revascularization vs. those that did not. ${ }^{19}$ These results indicate that some of the benefit of revascularization may arise from reducing modes of death other than heart failure (e.g., sudden death). Thus, while developing new ways to assess viability are of interest, they may be of greatest utility in planning revascularization procedures (identifying targets that are less likely to be scar) as well as providing patients a sense of whether symptoms of heart failure are likely to improve based upon the likelihood of reversible dyssynergy. Viability testing may also become helpful in identifying pathological substrates that could favorably respond to new interventions directed at regenerating myocardium such as cell based therapy. ${ }^{20}$ Unfortunately, as demonstrated by Benz et al., basing decisions on quantitative measurements of resting blood flow is probably not sufficient to make this distinction.

\section{Acknowledgements}

Supported by the National Heart Lung and Blood Institute (HL-061610, HL-130266), the Department of Veterans Affairs (1IO1BX002659, 1IK2BX004097-01A1), the Albert and Elizabeth Rekate Fund in Cardiovascular Medicine and the National Center for Advancing Translational Sciences (UL1TR001412).

\section{Disclosure}

Dr. Canty has served as a consultant for Lantheus Medical Imaging Inc. Dr. Lang has nothing to disclose.

\section{References}

1. Rahimtoola SH, Dilsizian V, Kramer CM, Marwick TH, Vanoverschelde JL. Chronic ischemic left ventricular dysfunction: from pathophysiology to imaging and its integration into clinical practice. JACC Cardiovasc Imaging 2008;1:536-55.

2. Kim RJ, Wu E, Rafael A, Chen EL, Parker MA, Simonetti O, Klocke FJ, Bonow RO, Judd RM. The use of contrast-enhanced magnetic resonance imaging to identify reversible myocardial dysfunction. N Engl J Med 2000;343:1445-53.

3. Canty JM, Fallavollita JA. Chronic hibernation and chronic stunning: A continuum. J Nucl Cardiol 2000;7:509-27.

4. Fallavollita JA, Perry BJ, Canty JM. F-18-2-deoxyglucose deposition and regional flow in pigs with chronically dysfunctional myocardium: Evidence for transmural variations in chronic hibernating myocardium. Circulation 1997;95:1900-9.

5. Selvanayagam JB, Jerosch-Herold M, Porto I, Sheridan D, Cheng AS, Petersen SE, Searle N, Channon KM, Banning AP, Neubauer $\mathrm{S}$. Resting myocardial blood flow is impaired in hibernating myocardium: A magnetic resonance study of quantitative perfusion assessment. Circulation 2005;112:3289-96.

6. Page BJ, Banas MD, Suzuki G, Weil BR, Young RF, Fallavollita JA, Palka BA, Canty JM Jr. Revascularization of chronic hibernating myocardium stimulates myocyte proliferation and partially reverses chronic adaptations to ischemia. J Am Coll Cardiol 2015;65:684-97.

7. vom Dahl J, Muzik O, Wolfe ED Jr, Allman C, Hutchins G, Schwaiger M. Myocardial rubidium- 82 tissue kinetics assessed by dynamic positron emission tomography as a marker of myocardial cell membrane integrity and viability. Circulation 1996;93:238-45.

8. Beanlands RS, deKemp R, Scheffel A, Nahmias C, Garnett ES, Coates G, Johansen HL, Fallen E. Can nitrogen-13 ammonia kinetic modeling define myocardial viability independent of fluorine-18 fluorodeoxyglucose? J Am Coll Cardiol 1997;29:537-43. 
9. Chareonthaitawee P, Kaufmann PA, Rimoldi O, Camici PG. Heterogeneity of resting and hyperemic myocardial blood flow in healthy humans. Cardiovasc Res 2001;50:151-61.

10. Stankewicz MA, Mansour CS, Eisner RL, Churchwell KB, Williams BR, Sigman SR, Streeter J, Patterson RE. Myocardial viability assessment by PET: (82)Rb defect washout does not predict the results of metabolic-perfusion mismatch. J Nucl Med 2005;46:1602-9.

11. Chien DT, Bravo P, Higuchi T, Merrill J, Bengel FM. Washout of (8)(2) Rb as a marker of impaired tissue integrity, obtained by listmode cardiac PET/CT: Relationship with perfusion/metabolism patterns of myocardial viability. Eur J Nucl Med Mol Imaging 2011;38:1507-15.

12. Timmer SAJ, Teunissen PFA, Danad I, Robbers L, Raijmakers P, Nijveldt R, van Rossum AC, Lammertsma AA, van Royen N, Knaapen $P$. In vivo assessment of myocardial viability after acute myocardial infarction: A head-to-head comparison of the perfusable tissue index by PET and delayed contrast-enhanced CMR. J Nucl Cardiol 2017;24:657-67.

13. Moody JB, Hiller KM, Lee BC, Poitrasson-Riviere A, Corbett JR, Weinberg RL, Murthy VL, Ficaro EP. The utility of (82)Rb PET for myocardial viability assessment: Comparison with perfusionmetabolism (82)Rb-(18)F-FDG PET. J Nucl Cardiol 2019;26:37486.

14. Benz DC, Ferro P, Safa N, Messerli M, von Felten E, Huang W, Patriki D, Giannopoulos AA, Fuchs TA, Grani C, Gebhard C, Pazhenkottil AP, Kaufmann PA, Buechel RR. Role of quantitative myocardial blood flow and (13)N-ammonia washout for viability assessment in ischemic cardiomyopathy. J Nucl Cardiol 2019. h ttps://doi.org/10.1007/s12350-019-01684-1.

15. Murthy VL, Bateman TM, Beanlands RS, Berman DS, BorgesNeto S, Chareonthaitawee P, Cerqueira MD, deKemp RA, DePuey EG, Dilsizian V, Dorbala S, Ficaro EP, Garcia EV, Gewirtz H,
Heller GV, Lewin HC, Malhotra S, Mann A, Ruddy TD, Schindler TH, Schwartz RG, Slomka PJ, Soman P, Di Carli MF, Directors SCCBo, Directors ABo. Clinical quantification of myocardial blood flow using PET: Joint position paper of the SNMMI cardiovascular council and the ASNC. J Nucl Med 2018;59:273-93.

16. Shah DJ, Kim HW, James O, Parker M, Wu E, Bonow RO, Judd RM, Kim RJ. Prevalence of regional myocardial thinning and relationship with myocardial scarring in patients with coronary artery disease. JAMA 2013;309:909-18.

17. Ling LF, Marwick TH, Flores DR, Jaber WA, Brunken RC, Cerqueira MD, Hachamovitch R. Identification of therapeutic benefit from revascularization in patients with left ventricular systolic dysfunction: inducible ischemia versus hibernating myocardium. Circ Cardiovasc Imaging 2013;6:363-72.

18. Velazquez EJ, Lee KL, Jones RH, Al-Khalidi HR, Hill JA, Panza JA, Michler RE, Bonow RO, Doenst T, Petrie MC, Oh JK, She L, Moore VL, Desvigne-Nickens P, Sopko G, Rouleau JL, Investigators S. Coronary-artery bypass surgery in patients with ischemic cardiomyopathy. N Engl J Med 2016;374:1511-20.

19. Bonow RO, Maurer G, Lee KL, Holly TA, Binkley PF, DesvigneNickens P, Drozdz J, Farsky PS, Feldman AM, Doenst T, Michler RE, Berman DS, Nicolau JC, Pellikka PA, Wrobel K, Alotti N, Asch FM, Favaloro LE, She L, Velazquez EJ, Jones RH, Panza JA. Myocardial viability and survival in ischemic left ventricular dysfunction. N Engl J Med 2011;364:1617-25.

20. Weil BR, Suzuki G, Leiker MM, Fallavollita JA, Canty JM Jr. Comparative efficacy of intracoronary allogeneic mesenchymal stem cells and cardiosphere-derived cells in swine with hibernating myocardium. Circ Res 2015;117:634-44.

Publisher's Note Springer Nature remains neutral with regard to jurisdictional claims in published maps and institutional affiliations. 